\title{
Pelatihan Packaging Dan Pemasaran Umkm Online Di Desa Sindangmulya, Kabupaten Bekasi
}

\author{
Kemal ABN, Dwiyan PPN ${ }^{1},{\text { Ahmad } \mathrm{HM}^{1} \text {, Muhammad SS }}^{1}$, Frally F $\mathrm{F}^{1}$, P Oktivasari $^{1}$ \\ ${ }^{1}$ Teknik Informatika dan Komputer, Politeknik Negeri Jakarta, Depok, Jawa Barat \\ Prihatin.oktivasari@tik.pnj.ac.id
}

\begin{abstract}
Abstrak
Dilema keberadaan Desa Sindang Mulya yang berada di kabupaten Bekasi provinsi Jawa Barat, dengan mayoritas penduduknya yang tidak bekerja. Adapun banyaknya warga yang sudah berumah tangga disana lebih memilih mengurus rumah tangga dan bekerja sebagai buruh pabrik. Sedangkan disisi lain ibu - ibu disana, sudah mempunyai usaha sendiri, yang dimana mempunyai produk rumahan seperti makanan dan minuman. Untuk produk makanannya itu berupa peyek, tekwan, sistik, pudding, cilok, kripik pisang coklat,dan lain-lain. Sedangkan, minumannya sendiri berupa The poci, dan susu kedelai. Produk mereka pasarkan ke Media Online karena Kurangnya bentuk kemasan yang menarik pada produk mereka, membuat harga jual produk pun mejadi rendah. Melalui Program Hibah Bina Desa (PHBD) Kemenristekdikti ini, dengan pelaksana para mahasiswa Politeknik Negeri Jakarta, Jurusan Teknik Informatika, yang berbasis pengabdian masyarakat melakukan Pelatihan packaging dan pemasaran produk Usaha Mikro Kecil dan Menengah (UMKM) secara online di Desa Sindang Mulya Kabupaten Bekasi.

Kegiatan ini dibuat untuk membantu para wirausaha agar mengembangkan packaging/kemasan mereka menjadi lebih menarik dan bernilai jual tinggi serta bisa dipasarkan secara online di website ataupun sosial media, antara lain Whatsapp, Instagram dan Facebook.
\end{abstract}

Kata kunci : UMKM, Kemasan, Online, Pelatihan

\section{Abstract}

The dilemma of the existence of Sindang Mulya Village in the Bekasi district of West Java province, with the majority of the population not working. The number of residents who are already married there prefer to take care of the household and work as factory workers. While on the other hand the women there, already have their own businesses, which have home-made products such as food and drinks. For food products in the form of peyek, tekwan, cystic, pudding, cilok, chocolate banana chips, and others. Meanwhile, the drink itself is in the form of a teapot and soy milk. Their products are marketed to Media Online because of the lack of attractive forms of packaging on their products, making the selling price of the product even lower. Through the Village Development Grant Program (PHBD) Kemenristekdikti, with the implementation of Jakarta State Polytechnic students, the Department of Informatics, which is based on community service, conduct online SME product packaging and marketing training in Sindang Mulya Village, Bekasi Regency.

This activity was created to help entrepreneurs develop their packaging to become more attractive and of high selling value and can be marketed online on websites or social media, including Whatsapp, Instagram and Facebook.

Keywords : UMKM, Packaging, Online, Training

\section{PENDAHULUAN}

Desa Sindang Mulya terletak di daerah kecamatan Cibarusah, kabupaten Bekasi, Jawa Barat. Desa Sindang Mulya ini memiliki cakupan 14 Rukun Warga (RW), serta 74 Rukun Tetangga (RT) dengan jumlah penduduk mencapai kurang lebih yaitu 33.243 jiwa., dengan mayoritas warga tidak bekerja dan sebagian ibu rumah tangganya mengolah produk olahan makanan dan minuman. Secara umum gambaran strategis Desa Sindang Mulya merupakan daerah yang memiliki luas $5.620 \mathrm{~km}$ dengan jumlah laki-laki 20,348 
jiwa serta 19,711 jiwa untuk perempuan dengan total 40,119 jiwa (BPN 2018), daerah ini sering kali dilewati truk kontainer yang berasal dari Kawasan Industri Cikarang menuju Jonggol ataupun sebaliknya sehingga sebenarnya sangat prospek untuk jualan di pinggir jalan. Sebagian masyarakat disana rata-rata berprofesi sebagai buruh pabrik untuk laki-laki dan untuk perempuan sebagian besar berprofesi Ibu rumah tangga yang mengikuti kegiatan PKK. Dari beberapa ibu-ibu PKK diantaranya memiliki industri rumahan yang memproduksi makanan ringan seperti keripik pisang, pempek, jajanan pasar, dan rengginang. Selain itu Desa Sindang Mulya memiliki banyak olahan industri rumah tangga juga seperti olahan makanan, antara lain peyek, tekwan, sistik, pudding, cilok, kripik pisang coklat, dan lain-lain. Produk masyarakat Sindang Mulya di berbagai sektor makanan mempunyai hasil yang sangat berpotensi pasar dikarenakan rasa yang dapat bersaing, akan tetapi dari sekian industri rumahan yang ada, hanya beberapa masyarakat desa Sindang Mulya yang mampu menembus penjualan besar pada pasar online maupun pasar tradisional, bahkan masih ada yang menjual hasil olahannya door to door ke masayarakat sekitar. Walaupun sudah menembus online pun, permasalahan pada nilai jual yang rendah pun ditemukan, karena sistem pemasarannya masih menggunakan metode konvensional dan kemasan seadanya tanpa ada logo maupun teknik untuk penampilan desain kemasan bahkan sebagian besar produk mereka hanya dibungkus dengan plastik dan diikat dengan tali rafia untuk menutup kemasan tersebut, serta masih banyak yang belum mendaftarkan usaha mereka pada sebuah platform jual online yang sering dikenal adalah e-commerce. Poin penting sebagai kunci penjualan produk adalah pengembangan bentuk kemasan serta visualisasi desain produk kemasan yang mampu meningkatkan daya tarik penjualan. Packaging kemasan yang menarik dan bagus merupakan nilai tambah bagi produk apapun yang dijual, dan itu bisa menjadi nilai tambah juga untuk wirausaha yang nanti akan menjadi terkenal.

UMKM sendiri adalah usaha yang dibuat oleh perorangan ataupun yang dibuat oleh badan usaha yang kriteria usaha nya itu sesuai dengan kriteria pada Undang - Undang No.20 pada tahun 2008. Oleh karena itu, UMKM sangat dibutuhkan di desa ini. Semakin banyak UMKM yang nanti terbentuk, dapat membantu mengurangi pengangguran. Selain itu di Sindang Mulya, banyak yang mempunyai wirausaha tetapi tidak terdaftar di UMKM desa, karena kurangnya wawasan masyarakat dalam memahami UMKM yang sebenarnya nantinya dapat memudahkan masyarakat dalam mensejahterahkan ekonomi. Selain itu jika tidak terdaftar, juga berakibat desa tidak mengetahui data pekerjaan yang digeluti oleh warganya.

Berdasarkan analisis kondisi situasi Desa Sindang Mulya, Tim Program Hibah Bina Desa (PHBD) PNJ, dari Program Studi Teknik Informatika bekerja sama dengan Himpunan Mahasiswa Teknik Informatika dan Komputer (HIMATIK) melalui pendanaan Kementerian Riset dan Teknologi Pendidikan Tinggi (Kemenristekdikti) akhirnya membuat program bantuan berupa pelatihan packaging dan teknik pemasara online produk UMKM agar UMKM yang berada di desa Sindang Mulya dapat dilirik oleh desanya sendiri, maupun sekitarnya, sampai ke luar Kabupaten Bekasi, sehingga diharapkan tingkat perekonomian warga desa Sindang Mulya menjadi meningkat. Selain itu produk akan menjadi lebih menarik dan meningkatkan kepercayaan konsumen dalam segi mendesain kemasan produk dan mepromosikan produk warga mereka masing masing dengan baik. Selain itu juga Tim PHBD memberikan bantuan fasiltas alat desain produk kemasan heatseal ke Desa Sindang Mulya untuk mentrigger keberlanjutan desain kemasan.

\section{METODE PENGABDIAN}

Metode pelaksanaan kegiatan yang dilakukan adalah berupa pelatihan. Pelatihan ini dilaksanakan selama 3 hari di Aula Balai Desa Sindang Mulya, dengan tahapan antara lain persiapan survey lokasi-pendekatan pejabat desa, persiapan barang - barang yang nantinya diberikan kepada wirausaha - wirausaha desa Sindang Mulya, dan monitoring-evaluasi melalui kuisioner.

Pelatihan dijadwalkan dengan topik setiap harinya berbeda, dengan mendatangkan beberapa narasumber yang berkeahlian dalam bidang masing-masing, seperti dihadirkan beberapa narasumber terkemuka dari Rumah Kemasan Bandung yaitu Bapak Mohammad Firsan, \& Bapak Ridha Rifandi, Bapak Boy, dan Ibu Syarifa. Pada hari pertama, diberikan bekal materi tentang packaging dan teori mengenai smartphone photography. Smartphone photography merupakan cara memotret produk dengan sudut dan angle yang bagus untuk mendapatkan hasil potret yang menarik. Pada hari kedua, mereka diberikan bekal bagaimana packaging dapat menarik minat para pembeli dengan memberikan inovasi dalam memodifikasi package produk mereka, dengan langsung praktek pada produk masing-masing, sembari 
narasumber memberikan pelatihan cara memodifikasi package tersebut. Acara penutup pada hari ketiga, para mahasiswa dari Politeknik Negeri Jakarta memberikan pengetahuan bagaimana cara memasarkan produk mereka yang sudah dibungkus oleh package yang menarik dengan cara online. Disini dijelaskan mengenai pemasaran di media sosial seperti INSTAGRAM, FACEBOOK, dan WHATSAPP. Pelatihan ini diharapkan dapat membantu packaging kemasan produk wirausaha dan pemasaran produknya secara online, sehingga meningkatkan perekonomian warga.

\section{a) Persiapan}

Proses persiapan dilakukan dengan berkunjung dan menyusun rencana untuk membuat persetujuan mengenai kegiatan pelatihan ke Kepala Desa R. Selpia Indriyani, SE dan Ketua UMKM Sindang Mulya, yang ditunjukkan pada Gambar 1 dan 2. Pada tahap persiapan ini juga melakukan survei kembali dan observasi secara intensif untuk mengindentifikasi potensi-potensi yang dimiliki oleh desa Sindang Mulya seperti jumlah masyarakat yang memiliki industri kecil dan juga masyarakat yang ingin mempelajari lebih tentang pengemasan produk. Selain itu juga dilakukan kerja sama dengan Rumah Kemasan (gambar 3) yang mana adalah lembaga di lingkungan Pemerintah Provinsi Jawa Barat yang dapat memberi materi kemasan produk untuk Industri Kecil Menengah (IKM) secara profesional.

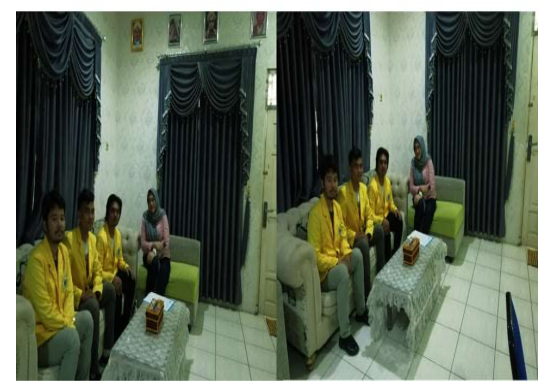

Gambar 1. Bertemu dengan Kepala Desa Sindang Mulya R. Selpia Indriyani, SE

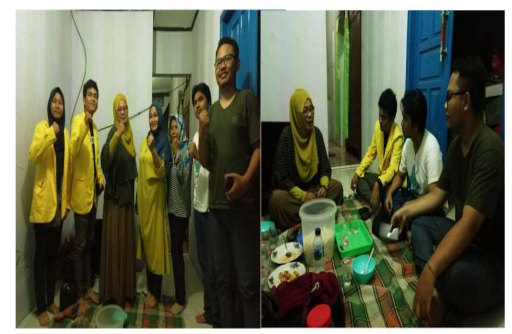

Gambar 2. Pertemuan dengan Ketua UMKM Desa Sindang Mulya

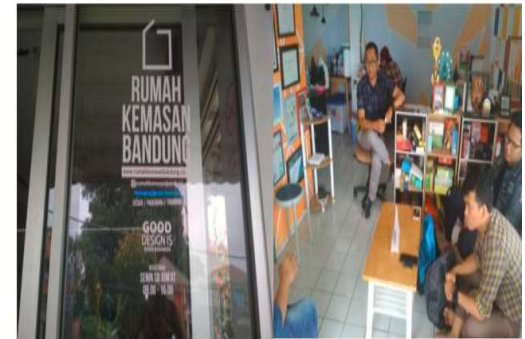

Gambar 3. Pertemuan untuk kerjasama dengan Rumah Kemasan Bandung

\section{b) Pelaksanaan Pelatihan}

Kegiatan pelatihan ini dilaksanakan selama 3 hari. Pada hari pertama (gambar 4 dan gambar 5), kegiatan dibuka oleh Ketua UMKM Desa Sindang Mulya serta Ketua Tim PHBD, kemudian dilanjutkan dengan materi mengenai smartphone photography dan packaging oleh Bapak Firsan Rumah Kemasan Bandung. Kegiatan pada hari kedua adalah praktek untuk membentuk packaging yang beragam polanya oleh Bapak Ridha Rifandi Bersama mahasiswa dan di hari terakhir adalah penyampaian materi mengenai pemasaran secara online oleh mahasiswa Politeknik Negeri Jakarta. Para peserta yang terdiri dari 25 ibu-ibu Rumah Tangga Desa Sindang Mulya membawa hasil olahan produk mereka masing-masing sebagai testing packaging tampak pada gambar 6 .

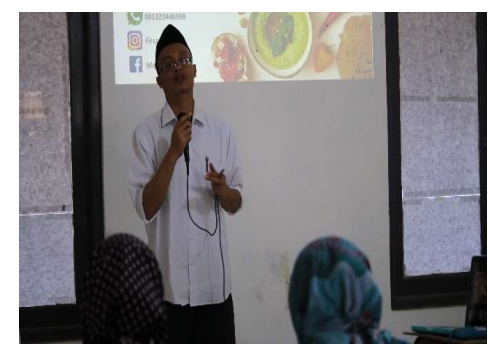

Gambar 4. Pembukaan Pelatihan Packaging dan Pemasaran UMKM Online di Desa Sindang Mulya

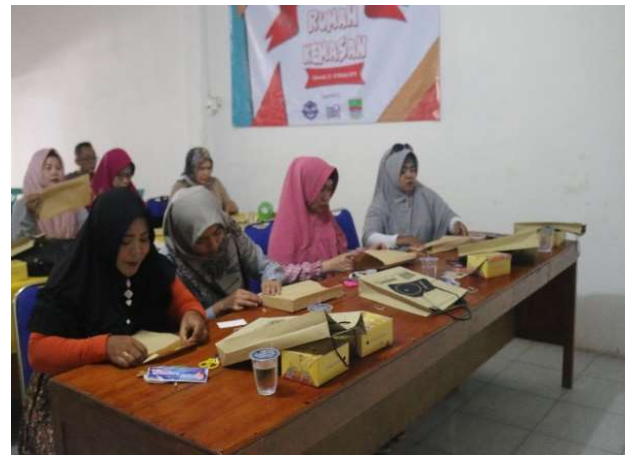

Gambar 5. Peserta ibu-ibu melakukan pelatihan kemasan di aula balai desa SindangMulya 
Pelatihan Packaging dan Pemasaran Online...

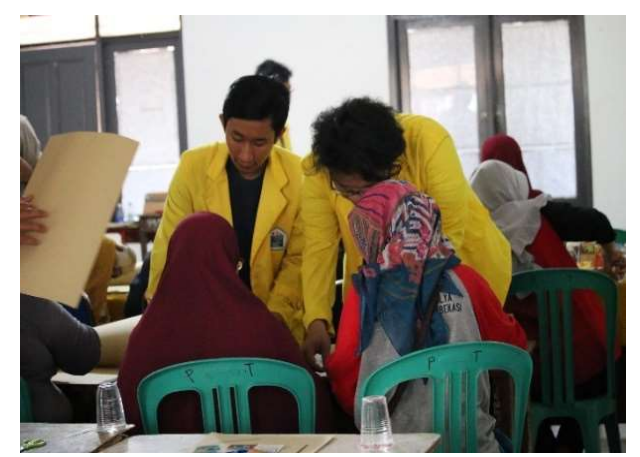

Gambar 6. Mahasiswa membantu perserta pelatihan kemasan

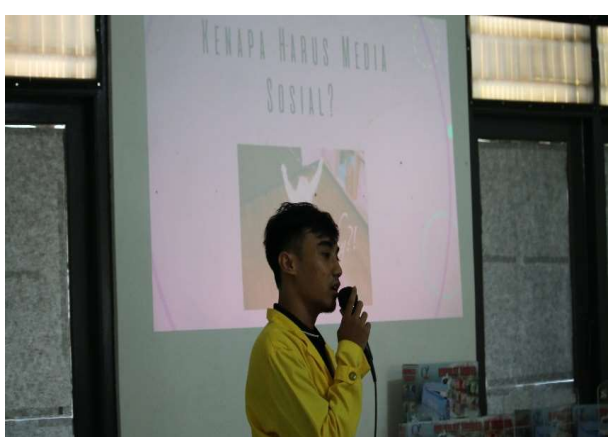

Gambar 7. Mahasiswa memberikan materi dan praktik pemasaran UMKM Online

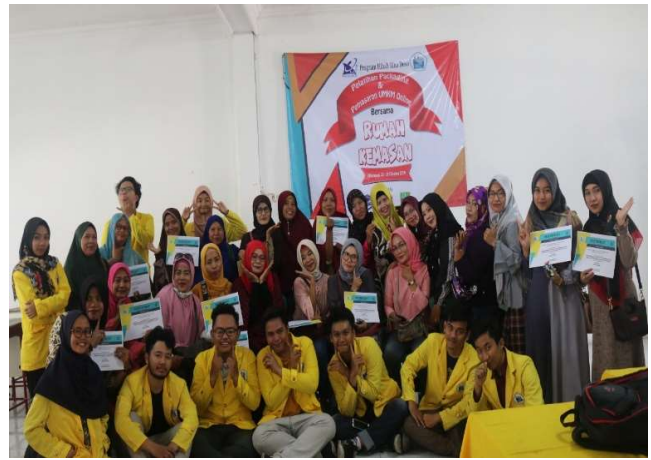

Gambar 8. Foto bersama setelah akhir sesi pelatihan dan penutupan kegiatan PHBD

\section{HASIL DAN PEMBAHASAN}

Setelah menjalani kegiatan pelatihan selama 3 hari dari tanggal 23 - 25 Oktober 2019, dan dilakukan proses evaluasi dan monitoring untuk 3 bulan kedepan untuk untuk keberlanjutan program yang telah diberikan ke warga Desa Sindang Mulya. Program evaluasi dilakukan dengan menyebarkan kuisioner kepada 25 peserta, yang mendapatkan hasil dari kuisioner, antara lain sangat membutuhkan kemasan produk, mereka memerlukan pelatihan kembali, serta kepuasan dari semua peserta terhadap pelatihan packaging dan pemasaran UMKM Online yang diadakan oleh Mahasiswa Politeknik Negeri Jakarta. Mahasiswa
Politeknik Negeri Jakarta pun dengan keahliannya memberikan fasilitas web untuk proses pemasaran UMKM desa Sindang Mulya, yang dapat dirujuk pada laman www.umkmsindangmulya.site, dan akan terus dikontrol dan dilanjutkan sehingga program berkelanjutan ke depannya.

\section{KESIMPULAN}

Hasil dari Program Hibah Bina Desa ini adalah:

1. UMKM terbentuk

2. Kemasan produk tercipta

3. memajukan UMKM Desa Sindang Mulya sehingga menjadi UMKM yang dilirik dalam desa maupun di luar desa kabupaten Bekasi

\section{SARAN}

Untuk kedepannya dibutuhkan kerjasama dengan perusahaan yang berbasis delivery online dan bisa dijual di website seperti tokopedia, GOJEK, GRAB, dan lainlain. Selain itu juga diharapkan kerjasama dengan beberpa ahli bidang Ijin Produksi Industri Rumah Tangga maupun dari BPOM maupun dari halal MUI, terkait beberapa produk yang belum mendapat serifikat ijin penjualan olahan makanan, yang mana harus ada standar kadaluwarsa dan halal.

\section{UCAPAN TERIMA KASIH}

Penulis mengucapkan terima kasih kepada KEMENRISTEKDIKTI yang telah memberikan hibah berupa dana untuk stimulus pada Program Hibah Bina Desa (PHBD) di Desa Sindang Mulya Kabupaten Bekasi, serta kepada Jurusan Teknik Informatika dan Komputer Politeknik Negeri Jakarta atas support waktu dalam pelaksanaan kegiatan PHBD ini.

\section{DAFTAR PUSTAKA}

https://sindangmulya.desa.or.id

https://id.wikipedia.org/wiki/Usaha_mikro_kecil_menen gah

https://www.ojk.go.id/sustainable-

finance/id/peraturan/undang-undang/Pages/UndangUndang-Republik-Indonesia-Nomor-20-Tahun-2008Tentang-Usaha-Mikro-Kecil,-dan-Menengah.aspx 